\title{
Immiscible poly(lactic acid)/poly( $\varepsilon$-caprolactone) for temporary implants: Compatibility and cytotoxicity
}

\author{
Pablo F.M. Finotti ${ }^{\mathrm{a}}$, Lidiane C. Costa ${ }^{\mathrm{b}}$, Ticiana S.O. Capote $^{\mathrm{c}}$, Raquel M. Scarel-Caminaga ${ }^{\mathrm{c}}$, \\ Marcelo A. Chinelatto ${ }^{\mathrm{a}, *}$ \\ a Department of Materials Engineering, Engineering School of São Carlos, University of São Paulo - USP, São Carlos, São Paulo 13563-120, Brazil \\ b Department of Materials Engineering, Federal University of São Carlos - UFSCar, São Carlos, São Paulo 13565-905, Brazil \\ c Department of Morphology, School of Dentistry at Araraquara, São Paulo State University - UNESP, Araraquara, São Paulo 14801-603, Brazil
}

\section{A R T I C L E I N F O}

\section{Keywords:}

PLA/PCL blends

Compatibility

Cytotoxicity

Mechanical properties

Morphology

\begin{abstract}
A B S T R A C T
This manuscript focuses on the effect of the addition of a low molecular weight triblock copolymer derived from $\varepsilon$-caprolactone and tetrahydrofuran (CT) on the compatibility and cytotoxicity of immiscible poly(lactic acid) (PLA) and poly( $\varepsilon$-caprolactone) (PCL) blends. Binary and tertiary PLA/PCL blends were prepared by melt mixing in a twin-screw extruder and their morphological, mechanical and thermal behaviors were investigated by scanning electron microscopy (SEM), tensile and Izod impact test, dynamic mechanical analysis (DMA) and differential scanning calorimetry (DSC). SEM micrographs showed the CT copolymer suppressed the coalescence phenomena and maintained the size of dispersed PCL domains at approximately $0.35 \mu \mathrm{m}$. Bioresorbable PLA/PCL blends containing 5 wt\% of CT copolymer exhibited a remarkable increase in ductility and improved toughness at room temperature. Although the CT copolymer increased the interfacial adhesion, the DMA results suggest it also acts as a plasticizer exclusively for the PCL phase. The cell viability evaluated by the XTT assay confirmed PLA/PCL blends compatibilized by CT copolymer exerted no cytotoxic effect.
\end{abstract}

\section{Introduction}

Over the past three decades, poly(lactic acid) (PLA) has received much attention due to its low environmental impact when disposed, since it is fully biodegradable by hydrolysis and enzymatic process (Auras et al. 2004). Additionally, PLA is a bio-based polymer, where the production of lactic acid is by bacterial fermentation of biomass (sugar or starch) or by chemical synthesis (Lunt, 1998; Rasal et al. 2010). Both characteristics have pointed to using PLA in applications that require low environmental impact polymers and susceptible to biological degradation at the end of their useful life, such as packaging (Chavalitpanya and Phattanarudee, 2013).

In addition to bio-based origin and biodegradability, PLA is one of the most promising polymers for biomedical applications due to the bioresorbability and biocompatible properties, making it highly desirable for temporary implants, as in coronary stents (Tamai et al., 2000; Ormiston and Serruys, 2009; Peng et al., 1996). Stents are structural implants with widespread clinical use in vascular intervention to reopen stenotic vessels for the treatment of coronary artery disease and peripheral arterial occlusive disease (Grabow, 2010). The main functions of a stent are the treatment of dissection and prevention of restenosis, events that occur in the first six months after coronary intervention (Colombo and Karvouni, 2000). After the vascular healing period, the permanent stents lose their functions and adverse side effects can appear, such as very late stent thrombosis (VLST).

The application of PLA as a biomaterial is limited by its poor toughness and brittleness, since generally the temperature is used below its glass transition temperature $(\mathrm{Tg})$, around $55-65^{\circ} \mathrm{C}$. According to the literature, blending PLA with other flexible polymers is an effective method to improve the toughness and increase the ductility of PLA. With a Tg of $-60{ }^{\circ} \mathrm{C}$, poli( $\varepsilon$-caprolactone) (PCL) is a rubbery biodegradable polyester, extensively used to improve the toughness and increase the flexibility of PLA (Nair and Laurencin, 2007; Wong et al., 2012; Williamson and Coombes, 2004). In addition to allowing the development and production of totally biodegradable blends, the mix of PLA with PCL has attracted scientific and technological interest in the biomedical field because PCL is also bioresorbable and biocompatible (Kweon et al. 2003; Woodruff and Hutmacher, 2010). Therefore, PLA/PCL blends are potential candidates to be used as biomaterial, particularly in applications that require mechanical support only some amount of time.

PLA/PCL blends are immiscible and the poor interfacial adhesion

\footnotetext{
* Corresponding author.

E-mail address: mchinelatto@sc.usp.br (M.A. Chinelatto).
} 
between phases is responsible for the low performance observed in these blends. A strategy to increase phase adhesion of immiscible polymer blends is the addition of a compatibilizer, usually a block copolymer where each block exhibits preferential interactions with the different phases in the blend (Work, 2004; Zeng et al., 2015). Thus, the compatibilizer tends to localize at the interface, improving the interfacial adhesion and allowing the stabilization and control of the morphology, key to achieve high mechanical performance in immiscible blends. Several studies have evaluated the influence of different compatibilizers on the mechanical properties and morphology of PLA/ PCL blends. Zhang et al. (2015) showed that the ductility of PLA/PCL blends containing 80 wt\% of PLA increased significantly with the increase of the amount of compatibilizer, a block copolymer derived from lactide and caprolactone (PLA-b-PCL). The addition of $5 \mathrm{wt} \%$ of PLA-b-PCL further enhanced the ductility of the blend with only a slight drop in tensile strength and modulus.

Tsuji et al. (2003) also investigated the compatibilizer effect of PLAb-PCL in the tensile properties of PLA/PCL blends. The amount of compatibilizer added in the blends was fixed at $10 \mathrm{wt} \%$ and the composition of PLA in the blends varied from 10 to $90 \%$ by weight. The addition of PLA-b-PCL concurrently improved the tensile stress, Young modulus and strain at break for PLA composition ranging from 50 wt\% to 80 wt\%.

Choi et al. (2002) studied the effect of two types of copolymers (lactide and caprolactone based polymers) on the morphology of the PLA/PCL (70/30 wt\%) blend. When a diblock copolymer with a mole ratio of caprolactone to lactide of 1.6 was used as compatibilizer, the dispersed domain size of the PCL decreased with the increase of the copolymer concentration up to $10 \mathrm{phr}$. However, the dimension of the dispersed PCL domains increased with the addition of the $15 \mathrm{phr}$ of the compatibilizer due to the formation of micelles in the PCL rich-phase. The presence of micelles reduced the interfacial adhesion in the blend.

Dell-Erba et al. (2001) studied the influence of triblock PLLA-PCLPLLA copolymer on the phase morphology of PLLA/PCL blends. Particularly for PLLA/PCL blends of different compositions (PLLA 70 wt\% and PCL 30 wt\%) the increase of triblock copolymer up to $2 \mathrm{wt}$ $\%$ decreases the PCL domains size. The addition of copolymer up to $5 \mathrm{wt} \%$ did not change the final morphology, indicating that the excess triblock copolymer also results in the micelle formation.

$\mathrm{Na}$ et al. (2002) investigated the mechanical properties of PDLLA/ PCL (80/20 wt\%) blends compatibilized with different concentrations of poly( $\varepsilon$-caprolactone-b-ethylene glycol) (PCL-b-PEG). The results showed that there is optimum copolymer concentration and the mechanical properties decrease probably due to the plasticizing effect of the compatibilizer when PCL-b-PEG copolymer is used at high concentration.

Chen et al. (2003) evaluated the compatibilizer effect of the copolymer ethylene oxide and propylene oxide on the mechanical properties of PLLA/PCL blends. The yield strain and strain at break values increased after adding the PCL and compatibilizer, but the other mechanical properties decreased.

This study investigated the effect of a commercially available triblock $\varepsilon$-caprolactone-tretahydrofuran- $\varepsilon$-caprolactone (CT) copolymer on immiscible PLA/PCL blends. PLA/PCL blends without and with 5 wt\% of CT were prepared by twin screw extrusion and the effect of the CT copolymer on the morphology and thermal and mechanical properties was investigated by scanning electron microscopy (SEM), dynamic mechanical analysis (DMA), differential scanning calorimetry (DSC) and tensile and Izod impact testing. The cytotoxic potential effect was also investigated by XTT-assay.

\section{Experimental}

\subsection{Materials}

Poly(lactic acid) (PLA grade: Ingeo 2003D), purchased from
Table 1

Properties of the polymers and copolymer used in this study.

\begin{tabular}{|c|c|c|c|c|c|}
\hline Materials & $\begin{array}{l}\text { MFI }{ }^{\mathrm{a}}[\mathrm{g} / \\
10 \mathrm{~min}]\end{array}$ & $\overline{M_{n}}[\mathrm{~g} / \mathrm{mol}]$ & $\frac{{\overline{M_{w}}}^{b}}{\overline{M_{n}}}$ & $\operatorname{Tm}\left({ }^{\circ} \mathbf{C}\right)^{\mathrm{d}}$ & $\begin{array}{l}\text { T }_{\text {onset }} \\
\left({ }^{\circ} \mathbf{C}\right)^{\mathrm{e}}\end{array}$ \\
\hline PLA & 7.5 & $138000^{b}$ & 1.62 & 153 & 365 \\
\hline PCL & 28.0 & $87000^{b}$ & 1.49 & 55 & 410 \\
\hline CT & - & $2000^{c}$ & - & 30 & 290 \\
\hline
\end{tabular}

${ }^{\text {a }}$ ASTM D1238: $190^{\circ} \mathrm{C}$ and $2.16 \mathrm{~kg}$;

${ }^{b}$ GPC: THF and $35^{\circ} \mathrm{C}$;

${ }^{\mathrm{c}}$ According to the manufacturer;

${ }^{\mathrm{d}} \mathrm{Tm}$ is melting temperature measured by differential scanning calorimetry (DSC).

e $\mathrm{T}_{\text {onset }}$ is onset decomposition temperature measured by thermogravimetric analysis (TGA).

NatureWorks Co. Ltd., of approximately $3.7 \%$ and $4.8 \%$ of D-isomer content and specific gravity of 1.24 . Poly( $\varepsilon$-caprolactone) (PCL grade: Capa 6500) obtained from Perstorp UK Ltd., is a non-toxic and biodegradable homopolymer with strain at break of over $700 \%$ and 17.5 MPa yield strength. The CT (Capa $7201 \mathrm{~A}$ ) added to immiscible PLA/PCL blends was kindly donated by Perstorp. CT is an ABA triblock copolymer, where A denotes blocks of the $\varepsilon$-caprolactone and $\mathrm{B}$ represents the block of the tetrahydrofuran. Table 1 shows the properties of the materials used in this study. The PLA was oven dried at $80^{\circ} \mathrm{C}$ for $8 \mathrm{~h}$ and the PCL was dried in a desiccator under vacuum for about a week before processing. CT copolymer was kept at low temperatures, as it is a solid wax at ambient temperatures.

Prior to the melt mixing, PLA and CT were placed in a beaker and kept in an oven at $40{ }^{\circ} \mathrm{C}$ for 15 minutes. After the complete melting of the triblock copolymer, PCL was added and the components were manually premixed.

\subsection{Processing conditions}

Premixed mixtures were melt-processed using a M19 intermeshing co-rotating twin screw extruder from B \& P Process and System, with a screw diameter of $19 \mathrm{~mm}$ and length to diameter ratio (L/D) of 25. The PLA/PCL blends were prepared using a temperature profile ranging from $170^{\circ} \mathrm{C}$ to $190{ }^{\circ} \mathrm{C}$ and $120 \mathrm{rpm}$ as screw speed. The blends were dried for $12 \mathrm{~h}$ in a vacuum oven at $50{ }^{\circ} \mathrm{C}$ and then injected to obtain the test specimens in a Battenfeld Plus $35 / 75$ equipment. The temperature profile for the injection molding ranges from $150{ }^{\circ} \mathrm{C}$ to $170{ }^{\circ} \mathrm{C}$ and the mold temperature was kept at $30^{\circ} \mathrm{C}$. Table 2 shows the composition of all PLA/PCL blends prepared.

\subsection{Characterization}

\subsubsection{Scanning electron microscopy (SEM)}

The morphological characterization was performed on the cryogenically fractured (liquid nitrogen) surfaces of PLA/PCL blends. An Inspect S50 (FEI) scanning electron microscope (SEM) was operated at $5 \mathrm{KV}$ accelerating voltage and a secondary electron detector was used. The particle size was measured by ImageJ image software. The particle average size $\left(D_{n}\right)$ of the dispersed phase was determined from

Table 2

Composition of PLA/PCL blends prepared by extrusion and injection molding.

\begin{tabular}{llll}
\hline Sample & PLA (wt\%) & PCL (wt\%) & CT(wt\%) \\
\hline PLA & 100 & - & - \\
PLA5PCL & 95 & 5 & - \\
PLA10PCL & 90 & 10 & - \\
PLA20PCL & 80 & 20 & - \\
PLA5PCLCT & 90 & 5 & 5 \\
PLA10PCLCT & 85 & 10 & 5 \\
PLA20PCLCT & 75 & 20 & 5 \\
PCL & - & 100 & - \\
\hline
\end{tabular}


approximately 300 particles manually measured for each blend from two or three distinct SEM images.

\subsubsection{Dynamic mechanical analysis (DMA)}

Dynamic mechanical analysis (DMA) was carried out on a DMA 8000, Perkin Elmer. Test bars were cut from Izod impact bar specimens (dimensions $35 \times 6.25 \times 3.2 \mathrm{~mm}$ ) and tested in the dual cantilever bending geometry at a frequency of $1 \mathrm{~Hz}$ and strain corresponding to an amplitude of $25 \mu \mathrm{m}$. Measurements were performed under nitrogen flow over a temperature range of -100 to $120^{\circ} \mathrm{C}$ and heating rate of $3{ }^{\circ} \mathrm{C} / \mathrm{min}$. Storage modulus (E') and $\tan \delta$ were recorded as a function of temperature.

\subsubsection{Differential scanning calorimetry (DSC)}

All samples were analyzed on a Perkin Elmer 8000 DSC equipped with an Intracooler II system for cooling. DSC curves were obtained using sample mass of c.a. $5.0 \mathrm{mg}( \pm 0.5 \mathrm{mg})$, heating rate of $10^{\circ} \mathrm{C} \mathrm{min}{ }^{-1}$ under nitrogen dynamic atmosphere flowing at $20 \mathrm{~mL} \mathrm{~min}^{-1}$, in a temperature interval of -70 to $190{ }^{\circ} \mathrm{C}$, using covered aluminum pans. The DSC was calibrated against indium as a temperature and enthalpy standard, according to the manufacturer's manual. The cooling and second heating scans are reported here.

\subsubsection{Mechanical testing}

Tensile properties of neat PLA and PLA/PCL blends were determined according to ASTM method D638 at $23^{\circ} \mathrm{C}$ and 50\% RH, using type I test specimens and an Instron 5569 universal testing machine with a Merlin analysis software. The test conditions used were: cross head speed of $5 \mathrm{~mm} / \mathrm{min}$ and load cell of $5 \mathrm{kN}$. Prior to testing, the specimens were conditioning for $48 \mathrm{~h}$ at $23^{\circ} \mathrm{C}$ and $50 \% \mathrm{RH}$. At least 6 specimens of each sample were tested and the average values were taken.

Izod impact tests were performed according to the standard ASTM 256 at $23^{\circ} \mathrm{C}$ and 50\% RH using a Ceast Resil Impactor. The pendulum used was of $1 \mathrm{~J}$ and the tests were carried out on notched specimens (dimensions $65 \times 12.5 \times 3.2 \mathrm{~mm}$ ). Samples were stored for $48 \mathrm{~h}$ at $23{ }^{\circ} \mathrm{C}$ and $50 \% \mathrm{RH}$ before testing. The reported values were the average of 10 measurements.

\subsubsection{In vitro cytotoxicity tests}

2.3.5.1. CHO-K1 cell culture. Chinese hamster ovary cells (CHO-K1) cells were cultured in 1:1 Ham-F10:D-MEM medium (Sigma ${ }^{\circ}$, St. Louis, MO) supplemented with 10\% FBS South America (Gibco, Invitrogen) and $1 \%$ antibiotic antimycotic solution stabilized (Sigma ${ }^{\circ}$ ), 1\% kanamycin (Gibco, Carlsbad, CA) in $25 \mathrm{~cm}^{2}$ culture flasks at $37{ }^{\circ} \mathrm{C}, 5 \% \mathrm{CO}_{2}$. Cells were used between the third and eighth passages.

\section{Eluate preparation.}

The eluate was prepared according to the ISO 10993-12, considering the surface area $\left(3 \mathrm{~cm}^{2} / \mathrm{mL}\right)$. PLA/PCL blends were immersed in 1:1 Ham-F10:D-MEM medium (Sigma , St. Louis, MO) without fetal bovine serum (FBS) were, shaking at $133 \mathrm{rpm}$ in an incubator (New Brunswick Scientific - Excella E24 Incubator Shaker Series) at $37^{\circ} \mathrm{C}$ for $72 \mathrm{~h}$.

2.3.5.2. XTT-based cytotoxicity assay. The technique principle is based on the cleavage of the yellow tetrazolium salt XTT by metabolically active cells, forming an orange formazan dye. Therefore, this conversion occurs only in viable cells. After $24 \mathrm{~h}$ of seeding, cells $\left(2 \times 10^{4}\right.$ cells seeded) were exposed for $24 \mathrm{~h}$ to the eluates in 24-well plates. Each well containing eluate was supplemented with $10 \%$ FBS. Negative control (NC) were cells with culture medium supplemented with $10 \%$ FBS without any treatment (untreated controls), while positive control (PC) the cells were treated with doxorubicin $\left(3 \mu \mathrm{g} \cdot \mathrm{mL}^{-1}\right)$ for $24 \mathrm{~h}$. All treatments were carried out in triplicate. After treatment, the cultures were washed with PBS solution and fresh culture medium supplemented with $10 \%$ FBS was added. After $24 \mathrm{~h}$ of incubation, the cultures were washed with PBS solution and immediately $500 \mu \mathrm{L}$ of DMEM without phenol red were added, followed by the addition of $60 \mu \mathrm{L}$ of the XTT/electron solution (50:1) (Cell Proliferation Kit II - Roche Applied Science). After $3 \mathrm{~h}$ reaction, the supernatant was transferred to a 96-well culture plate, and the absorbance was measured by a Microplate Reader (VersaMax, Molecular Devices, Sunnyvale, CA) at 492 and $690 \mathrm{~nm}$. The absorbance is directly proportional to the number of viable cells in each treatment after $24 \mathrm{~h}$ of exposure. Three independent experiments were conducted.

The Shapiro-Wilk test was used to assess the normality of the data. One-way analysis of variance (ANOVA) followed by the Tukey's test was applied to these data. Also, data from treated groups were compared to the negative control by the Dunnett's test. GraphPad statiscal package was used to perform the tests. Differences were considered statistically significant when $\mathrm{p}<0.05$.

\section{Results and discussion}

Fig. 1 shows SEM micrographs of fracture surfaces for neat PLA and PLA/PCL blends. Neat PLA shows a completely flat and homogeneous fracture surface with no holes [Fig. 1(a)]. On the other hand, SEM micrographs for PLA/PCL blends show a typical phase separation, which indicates PLA and PCL are immiscible in any proportion studied and the dispersed PCL particles exhibit a spherical shape. The increase in the PCL content in non-compatibilized binary PLA/PCL blends led to an increase in PCL particle size and a broadening of the particle size distribution, as observed in Table 3 and from the respective particle size distribution histograms. The particle average size increased from 0.31 to $0.71 \mu \mathrm{m}$, respectively, for the non-compatibilized PLA5PCL and PLA20PCL blends. During the processing of immiscible polymer blends, the breakup and coalescence of droplets occur simultaneously. Increasing the PCL content, the $\mathrm{D}_{\mathrm{n}}$ increased steadily due to the higher probability of collision between dispersed particles (Luy et al., 2000; Sundararaj, 2006). Thus, the coalescence effect becomes more pronounced and can explain the tendency for larger droplets, that is the increase in droplet size.

The average size of PCL droplets remained constant around $0.35 \mu \mathrm{m}$, regardless of the PCL content, due to the addition of $5 \mathrm{wt} \%$ of CT copolymer to immiscible PLA/PCL blends. Moreover, the width of the particle size distribution in compatibilized PLA/PCL blends is narrower than that observed in non-compatibilized blends and most of the PCL particle sizes of the compatibilized blends are below $0.5 \mu \mathrm{m}$. These results suggest the presence of CT copolymer contributes to the refinement of the morphology by the suppression of the coalescence phenomenon. The literature reports two mechanisms that explain the suppression of coalescence of the droplets for compatibilized blends. According to Sundararaj and Macosko (1995) as droplets approach each other, the blocks of the copolymer act like entropy springs, i.e., they compress to resist the van der Waals attraction. Therefore, the block copolymers at the interface prevent the coalescence process of the droplets.

In the second mechanism, the compatibilizer is convected out of the gap between the approaching droplets leading to a gradient in compatibilizer concentration. The tangential stress caused by the Marangoni stress immobilizes the interface, which retards the drainage of the film and suppresses coalescence (Van Puyvelde et al., 2001).

Although PLA is an enviromentally-friendly polyester with excellent biodegradability, its major drawbacks are its type of fracture, essentially brittle and low toughness, limiting its use in applications that 

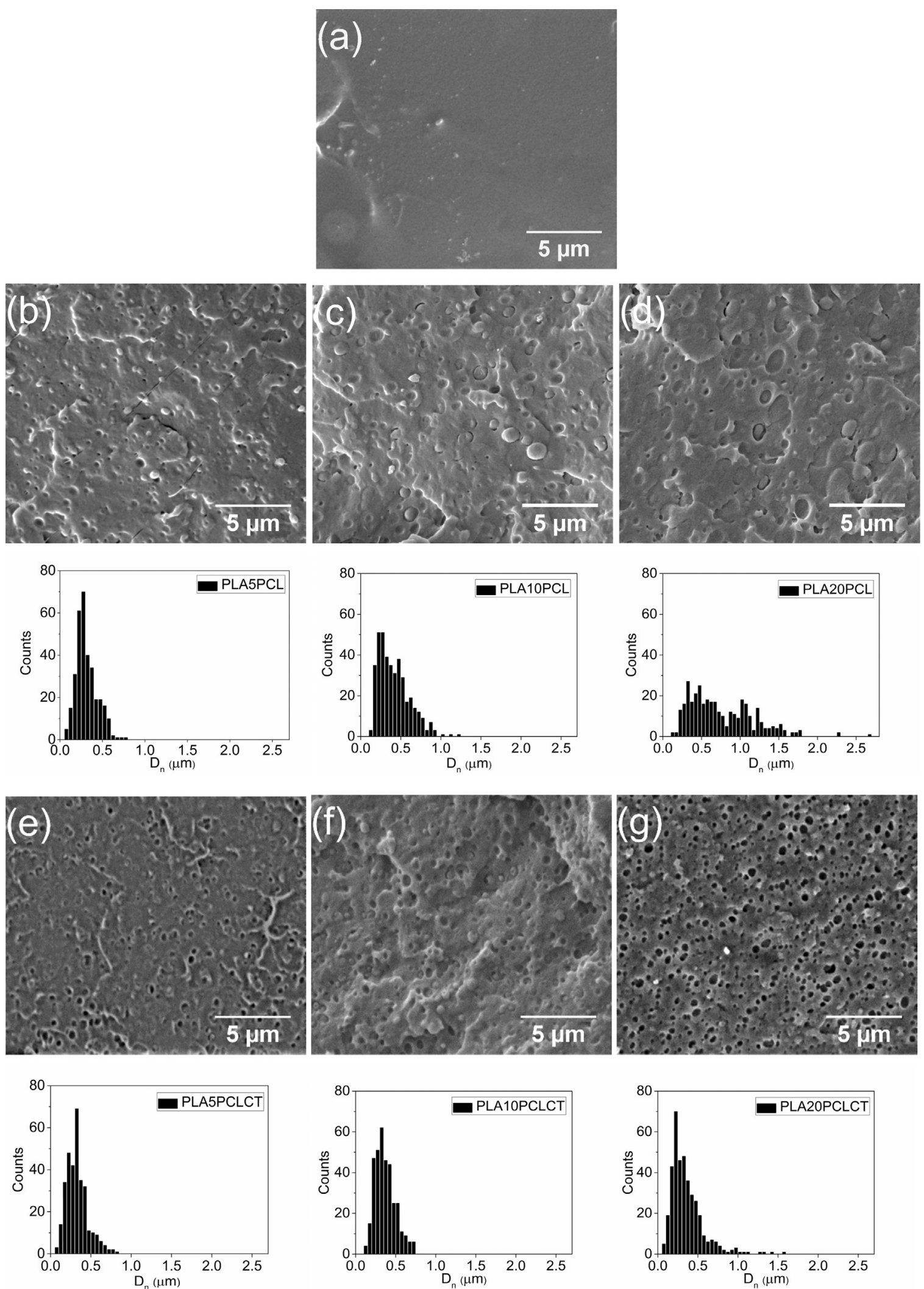

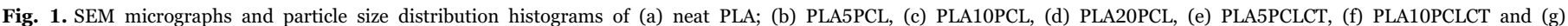
PLA20PCLCT. $\mathrm{D}_{\mathrm{n}}$ was manually measured for each blend.

require high mechanical performance. Fig. 2 shows mechanical behavior of the neat PLA and PLA/PCL blends under tensile load. The stress - strain curves shown in Fig. 2 were chosen because they represent the average mechanical behavior of each sample.
According to Fig. 2(a) and (b), neat PLA shows a brittle behavior, characteristic of glassy polymers. The strain at break was approximately $5 \%$, while the mean value of the Young's modulus is above $3200 \mathrm{MPa}$. Table 3 shows the main mechanical properties of neat PLA 
Table 3

Particle average size $\left(D_{n}\right)$ of the PCL phase and tensile properties of neat PLA and PLA/ PCL blends.

\begin{tabular}{llllll}
\hline Sample & $\mathrm{D}_{\mathrm{n}}(\mu \mathrm{m})$ & $\begin{array}{l}\text { Young's } \\
\text { modulus } \\
(\mathrm{MPa})\end{array}$ & $\begin{array}{l}\text { Tensile } \\
\text { yield } \\
\text { strength } \\
(\mathrm{MPa})\end{array}$ & $\begin{array}{l}\text { Strain at } \\
\text { break }(\%)\end{array}$ & $\begin{array}{l}\text { Izod } \\
\text { impact } \\
\text { resistance } \\
(\mathrm{J} / \mathrm{m})\end{array}$ \\
\hline PLA & - & $3210 \pm 120$ & $63.2 \pm 1.1$ & $4.6 \pm 1.2$ & $28.5 \pm 2.0$ \\
PLA5PCL & $0.31 \pm 0.12$ & $3100 \pm 170$ & $63.4 \pm 1.4$ & $7.3 \pm 3.0$ & $27.2 \pm 1.9$ \\
PLA10PCL & $0.41 \pm 0.19$ & $3050 \pm 30$ & $56.5 \pm 0.8$ & $14.4 \pm 1.8$ & $34.2 \pm 1.9$ \\
PLA20PCL & $0.76 \pm 0.41$ & $2800 \pm 20$ & $51.1 \pm 0.4$ & $25.0 \pm 3.2$ & $46.0 \pm 2.9$ \\
PLA5PCLCT & $0.33 \pm 0.13$ & $2800 \pm 60$ & $35.9 \pm 0.8$ & $103.9 \pm 22.8$ & $39.0 \pm 2.5$ \\
PLA10PCLCT & $0.37 \pm 0.13$ & $2800 \pm 50$ & $32.2 \pm 0.4$ & $36.8 \pm 3.3$ & $48.9 \pm 2.0$ \\
PLA20PCLCT & $0.36 \pm 0.21$ & $2500 \pm 20$ & $26.6 \pm 0.6$ & $45.4 \pm 9.9$ & $65.8 \pm 3.8$ \\
\hline
\end{tabular}

and PLA/PCL blends.

Adding up to $5 \mathrm{wt} \%$ of PCL to PLA and in the absence of CT copolymer, the blend shows no significant changes in mechanical behavior. Increasing the PCL amount in the non-compatibilized blends showed a reduction tendency in the Young's modulus and tensile yield strength and an increase in the strain at break.

Young's modulus and tensile yield strenght of compatibilized PLA/ PCL blends decreased in comparison with non-compatibilized blends. In the preparation step of the compatibilized blends, the PLA concentration was decreased by $5 \mathrm{wt} \%$ when CT copolymer was added. As PLA is the stiffest component of the system, the reduction in its concentration decreased the Young's modulus and tensile yield strenght of PLA/PCL blends, as shown in Table 3. Notwithstanding, the fracture mechanism of compatibilized blends showed a meaningful change at room temperature. Whereas in neat PLA or non-compatibilized PLA/PCL blends the fracture mechanism is essentially brittle with little or no plastic strain, in the compatibilized PLA/PCL blends, the fracture is very ductile and reaches a strain at break of approximately 104\% for PLA5PCLCT. However, the increase in the PCL concentration in the compatibilized blends resulted in an unexpected reduction in the strain at break. If the increase in the average size of the PCL particles is assumed negligible, the drastic decrease in the strain at break can be related to the reduction in the interfacial adhesion. As the droplet sizes remained practically constant, the increase in the PCL concentration resulted in a larger number of particles, hence, a larger surface area per unit mass of blend. The concentration of triblock copolymers on the interface of each droplet decreased and the adhesion between the dispersed phase and the matrix was reduced.

One of the main limitations of PLA is its low toughness, considered inadequate for many applications. According to Table 3, the Izod impact resistance of neat PLA is approximately $29 \mathrm{~J} / \mathrm{m}$. The enhancement in the PCL amount on the mixtures decisively contributed to the

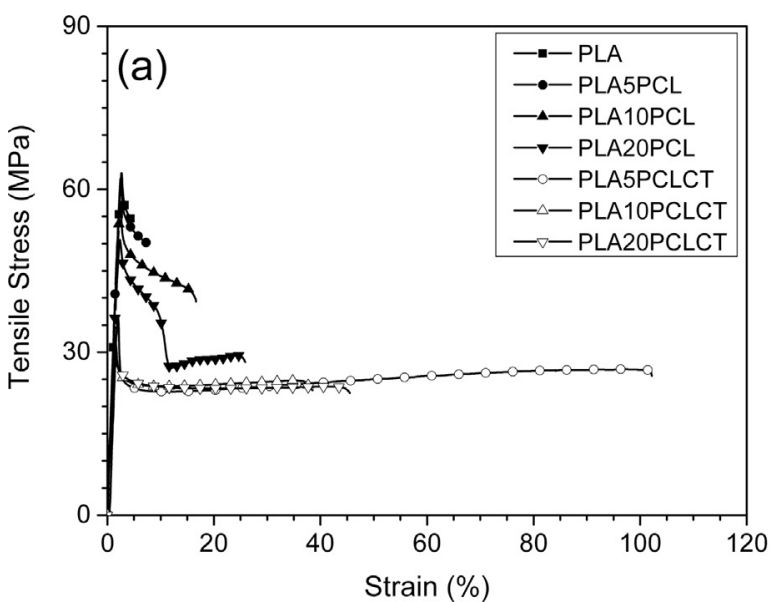

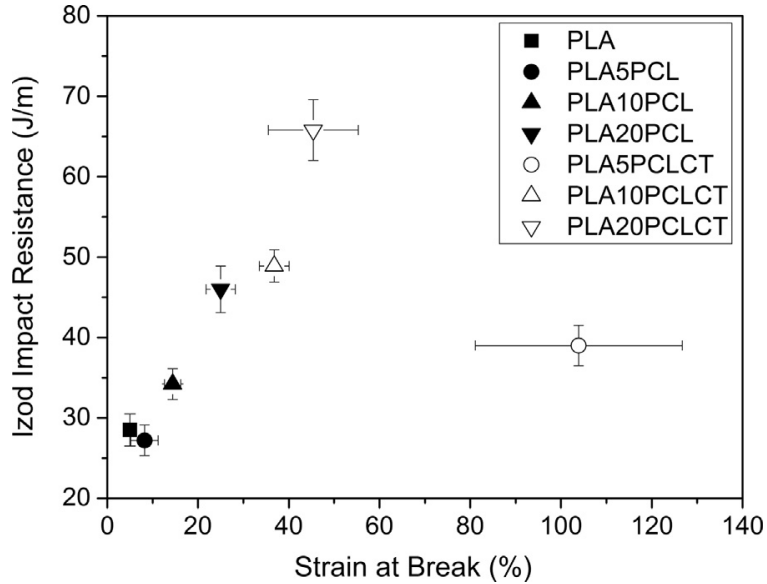

Fig. 3. Izod impact resistance versus strain at break for neat PLA and PLA/PCL blends.

toughening of the blends, where the compatibilized blends showed better performance than the non-compatibilized ones. This fact shows that PLA/PCL blends were actually toughened with the CT copolymer.

PLA is recognized for its brittleness and low toughness and Fig. 3 shows these two mechanical properties for neat PLA and PLA/PCL blends.

The results shown in Fig. 3 suggest that the Izod impact resistance and ductility, evaluated by strain at break, are affected differently by the presence of the CT copolymer and amount of PCL. The strain at break reached the maximum value when the PCL and CT copolymer amounts were $5 \mathrm{wt} \%$ probably due to the high interfacial adhesion. Although the presence of the CT copolymer increased the Izod impact resistance of the blends, the toughness mechanism is more sensitive to PCL amount, following an increasing tendency with the increase in the dispersed phase concentration.

Fig. 4 shows the storage modulus (E') and $\tan \delta$ as a function of temperature of the neat PLA and PLA/PCL blends. DMA curves were divided into two regions, one in the vicinity of the Tg of PCL (Fig. 4(a) and (b)) and the other in the vicinity of the Tg PLA (Fig. 4(c) and (d)). For neat PLA (Fig. 4(a)) in the $-100{ }^{\circ} \mathrm{C}-40{ }^{\circ} \mathrm{C}$ range the E' continually decreased with the temperature increase. The absence of peaks in its respective $\tan \delta$ curve (Fig. 4(b)) indicates that there are no primary or secondary transitions in this temperature range. The addition of PCL decreased the E' values of all blends, as expected. Such a decrease E' at approximately $-54{ }^{\circ} \mathrm{C}$ accompanied by the peaks in $\tan \delta$ curves is due to the glass transition of PCL. This drop in E' at $-54^{\circ} \mathrm{C}$ is directly proportional to the PCL concentration.

The peaks of the tan $\delta$ curves (Fig. 4(b)) for compatibilized blends are broader when compared with the non-compatibilized blends with

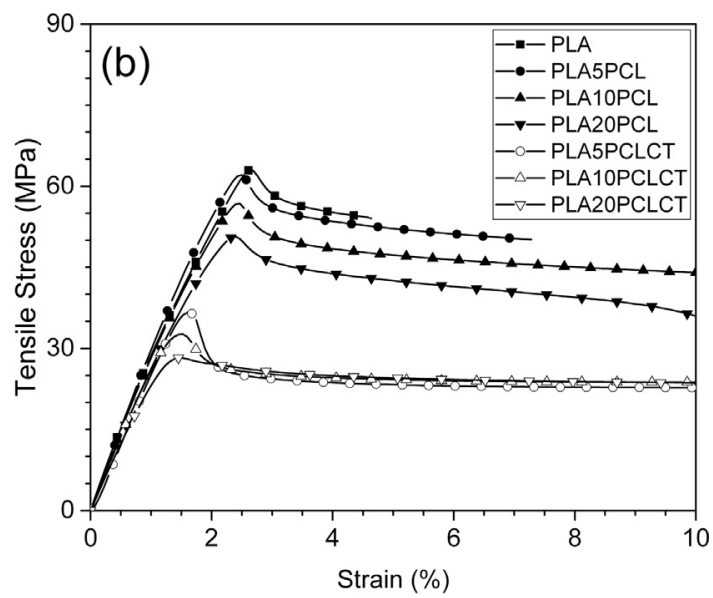

Fig. 2. (a) Full-range tensile stress - strain curves and (b) tensile stress - strain curves showing the 0-10\% strain range for neat PLA and PLA/PCL blends. 

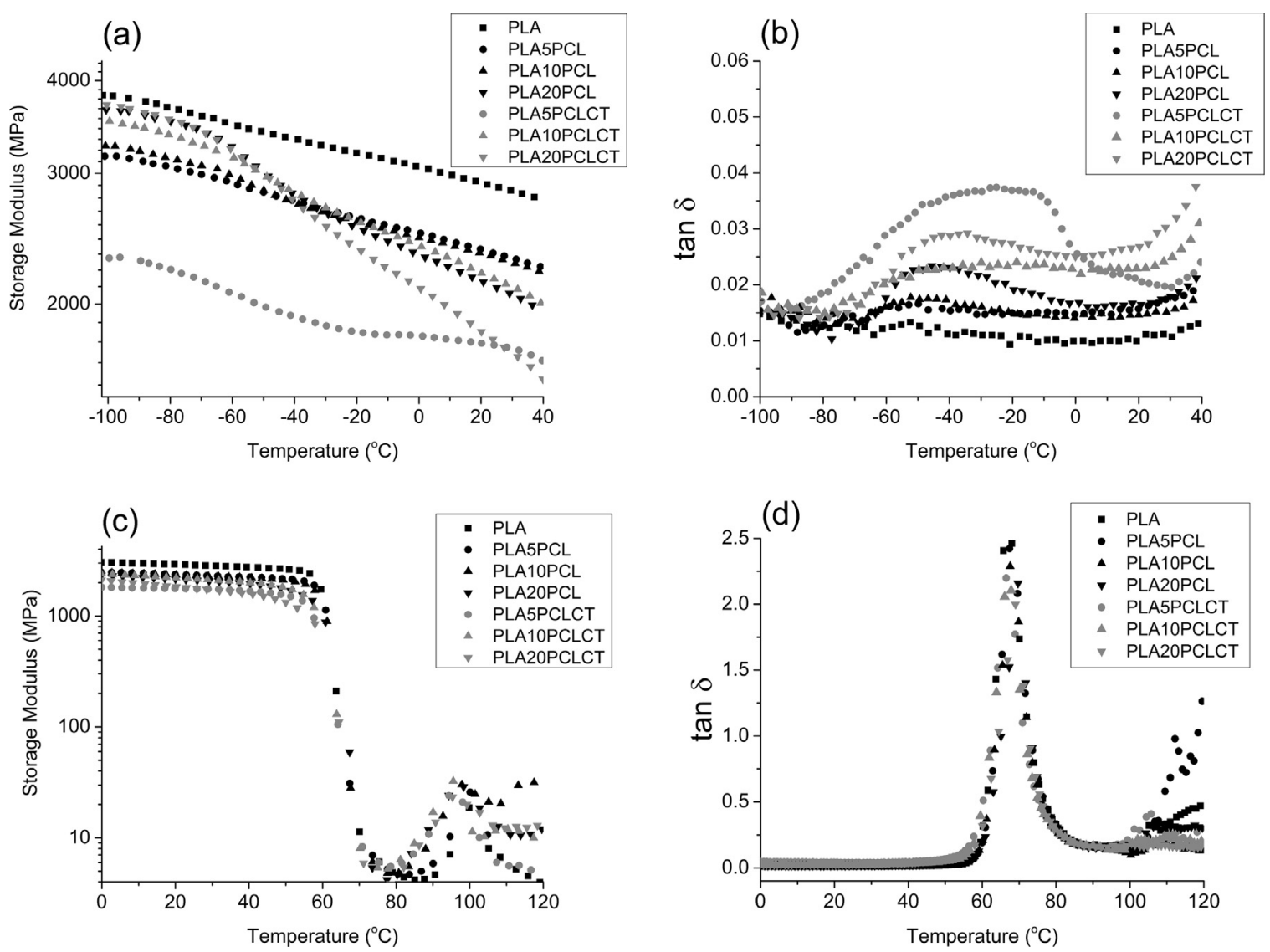

Fig. 4. Storage modulus and tan $\delta$ curves of neat PLA and PLA/PCL blends plotted against temperature - (a) and (b) from $-100{ }^{\circ} \mathrm{C}$ to $40{ }^{\circ} \mathrm{C}$; (c) and (d) from $0{ }^{\circ} \mathrm{C}$ to $120{ }^{\circ} \mathrm{C}$.

same PCL amount, which start at temperatures below the Tg of PCL. The lowering of $\mathrm{Tg}$ reveals a possible plasticizer effect of the CT copolymer in the PCL phase. The chemical structure of the CT, where each molecule has $\varepsilon$-caprolactone segments as end blocks combined with its low molecular weight may be responsible for the plasticizing effect in the PCL phase. The plasticizer effect of the triblock copolymer also explains the higher intensity of the $\tan \delta$ peaks due to the increase in the viscous response. In addition, it is observed that the maximum peaks shift to temperatures above the Tg of PCL for compatibilized PLA/PCL blends, probably due to the restriction of mobility between the polymer chains. This restriction of mobility can be assigned to an improvement in the interfacial adhesion between PLA and PCL phases. With the increase of the PCL amount, the plasticizer effect of the CT copolymer becomes less noticeable and the interfacial adhesion is reduced. This behavior explains the decrease of strain at break with the increase in PCL for compatibilized blends.

The interpretation of the E' and tan $\delta$ curves in the $0{ }^{\circ} \mathrm{C}$ and $120^{\circ} \mathrm{C}$ temperature range (Fig. 4(c) and (d)) is limited due to the overlap between Tg of the PLA and Tm of the PCL, which occurs in the heating at approximately $60^{\circ} \mathrm{C}$. The E' values of neat PLA and PLA/PCL blends decreases continuously until $60^{\circ} \mathrm{C}$ (Fig. 4(c)) and from this temperature the drop is pronounced and accompanied by a peak at $67^{\circ} \mathrm{C}$ in the $\tan \delta$ curve (Fig. 4(d)). The peaks observed at around $100{ }^{\circ} \mathrm{C}$ in $\mathrm{E}$ ' curves are attributed to the cold crystallization of PLA.

Fig. 5 shows the DSC curves of the controlled cooling and second heating runs of PLA, PCL and PLA/PCL blends. The Tg of PLA (a)

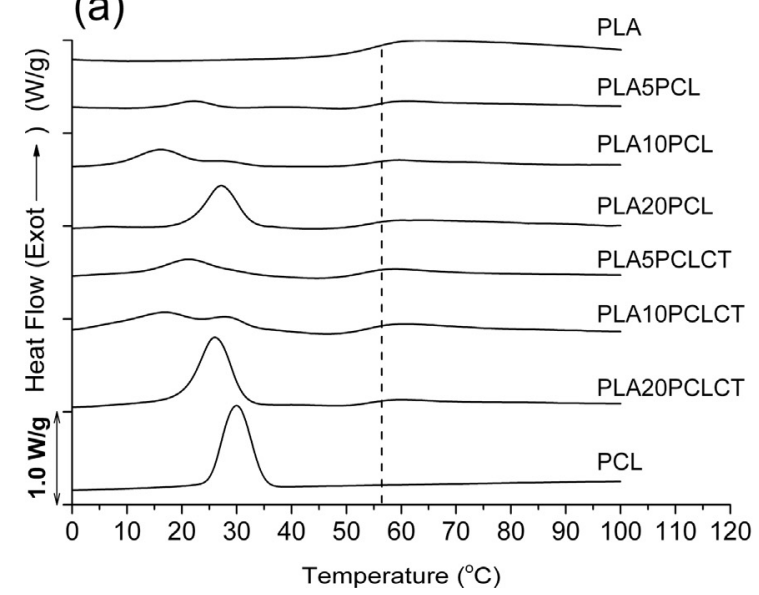

(b)

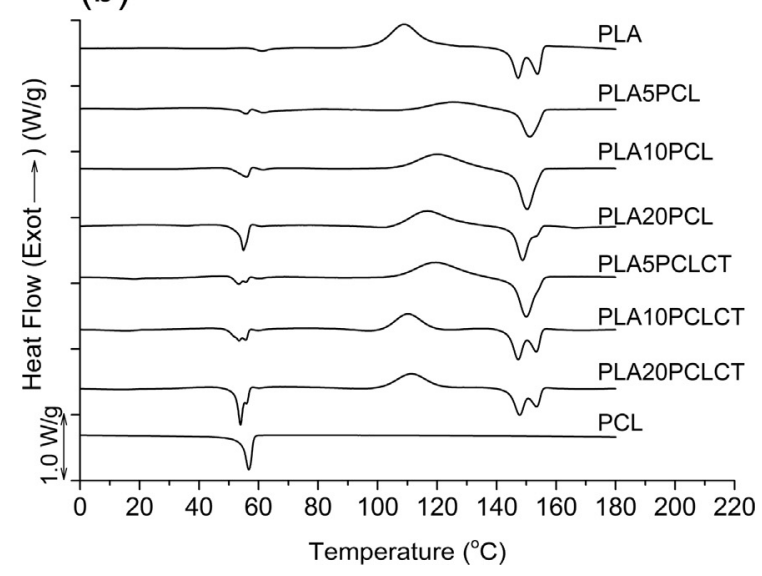

Fig. 5. DSC curves of PLA, PCL and blends: (a) cooling and (b) second heating runs. 
evaluated is in the $55-59^{\circ} \mathrm{C}$ temperature range, and is practically overlapped with the Tm of PCL around $53-56{ }^{\circ} \mathrm{C}$. The DSC curves of the second heating for non-compatibilized show both thermal transitions. The peaks at lower temperatures are due to the melting of the PCL phase and the inflection at higher temperature is characteristic of glass transition of the PLA matrix.

Although such thermal transitions are visible in some DSC thermograms, their quantification from heating curves is imprecise. The DSC cooling curves are shown here because different from the heating curves, where Tg of the PLA and Tm of the PCL occur at the same temperature range, upon cooling the thermal transitions of PLA and PCL happen at a different temperature range and the effect of the CT copolymer in each phase can be better evaluated. During cooling, the $\mathrm{Tg}$ of the PLA remains at around $55^{\circ} \mathrm{C}$, but the crystallization process of the PCL starts at approximately $35^{\circ} \mathrm{C}$.

The dashed line in the DSC curves of the controlled cooling (Fig. 5(a)) is a guide for eyes. It shows the Tg of PLA was not influenced by the PCL amount, which confirms that PLA and PCL are immiscible. The addition of the CT copolymer also did not change the $\mathrm{Tg}$ of PLA, suggesting the low molecular weight copolymer had no plasticizing effect on the PLA matrix. Crystallization temperature (Tc) of PCL in binary and ternary blends decreased when compared to that determined for neat PCL and the crystallization exothermic peaks become broader. Castillo et al. (2010) studied the crystallization kinetics of PLLA-b-PCL diblock copolymers and concluded the depression in the Tc, Tm, $\Delta \mathrm{Hc}$ and $\Delta \mathrm{Hm}$ of PCL was probably related to the fractionated crystallization phenomenon induced by confinement effects. For immiscible PLA/PCL blends, the PCL chains are confined in micro-domains surrounded by solid PLA. Such confinement decreased the Tc and $\Delta \mathrm{Hc}$ of PCL. The fractionated crystallization may have also been responsible for the broadening of the crystallization exothermic peaks. In general, the crystallization enthalpy $\left(\Delta \mathrm{H}_{\mathrm{c}}\right)$ of the PCL phase in compatibilized blends is higher in comparison to those of noncompatibilized blends. The presence of the compatibilizer may increase the mobility of PCL chains or even provide nucleation sites and decrease the energy barrier for the crystallization process. The addition of CT copolymer tends to increase the $\triangle \mathrm{Hc}$ of the PCL in comparison with non-compatibilized blends (Table 4).

In the DSC curves of the second heating for compatibilized PLA/ PCL blends (Fig. 5(b)), the melting process of PCL is characterized by two endothermic peaks. The lower temperature peak can be associated with the migration of a part of the CT copolymer to the PCL phase since its terminal segments are composed of $\varepsilon$-caprolactone blocks, as mentioned earlier. The high $\varepsilon$-caprolactone concentration combined with its low molecular weight allows the migration of the CT copolymer from the PLA/PCL interface to the interior of the PCL rich-phase, decreasing the size and degree of perfection of the crystalline lamellae, hence lowering the Tm of the PCL. The second melting peak at $56{ }^{\circ} \mathrm{C}$ is typical of the neat PCL.
The exothermic peak at $108{ }^{\circ} \mathrm{C}$ is due to the crystallization process (cold crystallization) of PLA. As the cold crystallization enthalpy $(\Delta \mathrm{Hcc})$ value is comparable to melting enthalpy $(\Delta \mathrm{Hm})$ within experimental errors, the crystallization of PLA upon cooling is negligible. The presence of PCL increased the cold crystallization temperature (Tcc) of PLA, but the addition of CT copolymer made this effect less pronounced. A possible explanation for the increase in the cold crystallization temperature of the PLA matrix in non-compatibilized blends is the reduction of the driving force for crystallization process caused by the presence of the PCL. The reduction in the driving force shifts the cold crystallization to higher temperatures, as shown in Fig. 5(b).

The addition of CT copolymer seems to compensate for the PCL effect on the PLA crystallization process because the compatibilizer probably acts as a nucleation agent and reduces the PLA cold crystallization temperature.

The endothermic peak at approximately $150{ }^{\circ} \mathrm{C}$ is attributed to the melting process of the PLA crystalline phase. However DSC thermograms of the neat PLA, PLA20PCL, PLA10PCLCT and PLA20PCLCT show two endothermic peaks related with the PLA melting. There are some explanations for the double melting peaks phenomenon in the literature. PLA can crystallize into two different crystal structures. The $\alpha$-form that melts at higher temperature and the $\beta$-form that melts at lower temperature (Zhou et al., 2006; Yasuniwa et al., 2006). The presence of the two endothermic peaks can also be explained by the growth of small crystals, which at low heating rates there is enough time for these small crystals to melt and recrystallize before melting again (Di Lorenzo, 2006; Gui et al., 2013). Shan et al. (2010) suggest the peak located at a higher temperature is a result of the melting of the thicker lamellae, possibly generated during the injection molding process. In contrast, the lower temperature peak is related to the crystallization of the sample during the annealing process.

Luyt and Gasmi (2016) studied the influence of PCL on the crystallization process of PLA in PLA/PCL blends by DSC and StepScan DSC. Standard DSC experiments showed only one endothermic peak at $150^{\circ} \mathrm{C}$ for all blend compositions due to the melting of PLA. However, StepScan analyses revealed a complex overlap of endothermic and exothermic peaks between the reversible and irreversible components in the $140-160{ }^{\circ} \mathrm{C}$ temperature range, strongly influenced by the cold crystallization of PLA. The authors concluded PCL influences the cold crystallization mechanism of PLA.

According to Fig. 5(b), for PLA/PCL blend with low PCL concentration, the melting of PLA exhibited only one endothermic peak, while blends containing higher PCL concentrations resulted in two melting peaks. Besides the influence of PCL, the results suggest its concentration exerts a remarkable effect on the cold crystallization mechanism and melting process of PLA.

The evaluation of the CT effect on the cell viability is also important in PLA/PCL blends for biomedical applications, particularly prepared by non-reactive compatibilization such as in this study. XTT assay has

Table 4

DSC data of PLA, PCL and PLA/PCL blends.

\begin{tabular}{|c|c|c|c|c|c|c|c|c|}
\hline \multirow[t]{3}{*}{ Sample } & \multicolumn{3}{|c|}{ Cooling curves } & \multicolumn{5}{|c|}{ Second heating curves } \\
\hline & \multirow{2}{*}{$\begin{array}{l}\text { PLA } \\
\operatorname{Tg}\left({ }^{\circ} \mathrm{C}\right)\end{array}$} & \multicolumn{2}{|l|}{ PCL } & \multirow{2}{*}{$\begin{array}{l}\mathrm{PCL} \\
\mathrm{Tm}\left({ }^{\circ} \mathrm{C}\right)\end{array}$} & \multicolumn{4}{|l|}{ PLA } \\
\hline & & $\operatorname{Tc}\left({ }^{\circ} \mathrm{C}\right)$ & $\Delta \mathrm{Hc}^{\mathrm{a}}(\mathrm{J} / \mathrm{g})$ & & Tcc $\left({ }^{\circ} \mathrm{C}\right)$ & $\Delta \operatorname{Hcc}^{\mathrm{a}}(\mathrm{J} / \mathrm{g})$ & $\operatorname{Tm}\left({ }^{\circ} \mathrm{C}\right)$ & $\Delta \mathrm{Hm}^{\mathrm{a}}(\mathrm{J} / \mathrm{g})$ \\
\hline PLA & 57 & - & - & - & 108 & 22 & $147-154$ & 24 \\
\hline PLA5PCL & 57 & 22 & 16 & 56 & 124 & 13 & 151 & 15 \\
\hline PLA10PCL & 56 & 16 & 34 & 56 & 120 & 26 & 150 & 27 \\
\hline PLA20PCL & 57 & 27 & 23 & 55 & 116 & 22 & $148-153$ & 23 \\
\hline PLA5PCLCT & 53 & 21 & 38 & $53-56$ & 119 & 29 & 150 & 28 \\
\hline PLA10PCLCT & 53 & 16 & 33 & $53-56$ & 110 & 29 & $147-153$ & 28 \\
\hline PLA20PCLCT & 56 & 26 & 39 & $54-56$ & 111 & 26 & $148-153$ & 25 \\
\hline PCL & - & 30 & 51 & 57 & - & - & - & - \\
\hline
\end{tabular}

\footnotetext{
${ }^{\text {a }}$ Enthalpy values were normalized by the weight fraction of each polymer in the blend.
} 


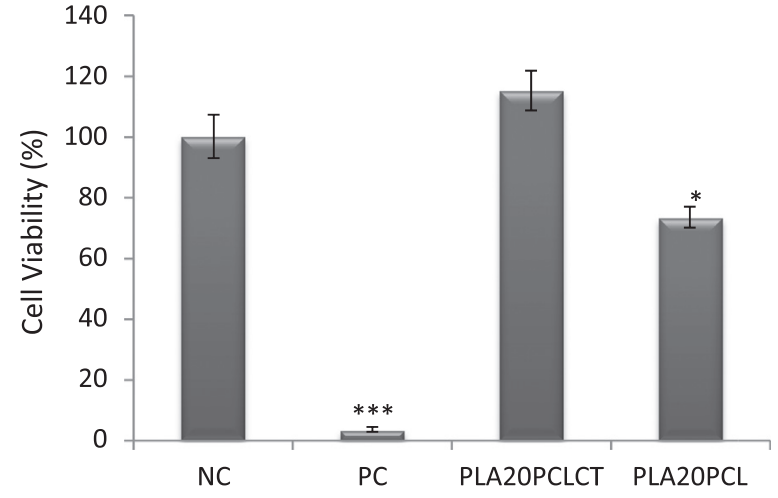

Fig. 6. Cytotoxicity assay. Cell viability (\%) of CHO-K1 by XTT assay after treatments. Columns $=$ mean; bars $=$ standard error. ${ }^{*}=\mathrm{p}<0.05 ;{ }^{* * *}=\mathrm{p}<0.0001$ in relation to the NC (Dunnett's).

been used as a routine tool in cell quantification to study the cytotoxicity of the materials since it measures the metabolic activity of cells (Silva et al., 2008). The Chinese hamster ovary (CHO) cell line has been widely used for studies measuring the cytotoxicity and genotoxicity of drugs (Yalkinoglu et al., 1990). The measurements were only performed in PLA/PCL blends with $20 \mathrm{wt} \%$ of PCL due to the good balance between toughness and ductility. Cell viability evaluated by XTT showed that no statistical differences were found between PLA20PCLCT and the negative control (NC), indicating it did not exhibit cytotoxicity (Fig. 6). Indeed, since the PLA20PCLCT showed $115,2 \%$ of viability it means that it promoted slight higher viability than the NC. On the other hand the PLA20PCL resulted in 73,3\% of viability, demonstrating a slight damage to the mitochondrial activity of the CHO cell, but significantly lower than doxorubicin, a potent chemotherapy, and typical positive control (PC) for cytotoxicity tests. Cell viability was scored according to the method of Sjögren et al. (2000). If cell viability exceeded $90 \%$, the material was deemed noncytotoxic. For cell viability at $60-90 \%$ range, the material was regarded as slightly cytotoxic.

\section{Conclusions}

CT copolymer is an efficient alternative of non-reactive compatibilization of immiscible PLA/PCL blends. The size of PCL droplets in compatibilized blends remained practically constant, regardless of the dispersed phase concentration. The addition of $5 \mathrm{wt} \%$ of CT copolymer enhanced the ductility of the blends at room temperature, mainly for blends with 5 wt\% PCL. The toughness of compatibilized PLA/PCL blends was also improved, but in this case the improvement was greater for blends with high PCL concentration. Compatibilized PLA/ PCL blends showed no cytotoxic effect, which indicates they are promising for use in biomedical applications, particularly as temporary absorbable implants.

\section{Acknowledgements}

The authors gratefully acknowledge the financial support granted to this research by Coordination for the Improvement of Higher Education Personnel (CAPES), Brazil.

\section{References}

Auras, R., Harte, B., Selke, S., 2004. An overview of polylactides as packaging materials. Macromol. Biosci. 4, 835-864.

Castillo, R.V., Müller, A.J., Raquez, J.-M., Dubois, P., 2010. Crystallization kinetics and morphology of biodegradable double crystalline plla-b-pcl diblock copolymers. Macromolecules 43, 4149-4160.

Chavalitpanya, K., Phattanarudee, S., 2013. Poly(lactic acid)/polycaprolactone blends compatibilized with block copolymer. Energy Proced. 34, 542-548.

Chen, C.-C., Chueh, J.-Y., Tseng, H., Huang, H.-M., Lee, S.-Y., 2003. Preparation and characterization of biodegradable pla polymeric blends. Biomaterials 24, 1167-1173.

Choi, N.-S., Kim, C.-H., Cho, K.Y., Park, J.-K., 2002. Morphology and hydrolysis of pcl/ plla blends compatibilized with p(lla-co-ecl) or p(lla-b-ecl). J. Appl. Polym. Sci. 86, 1892-1898.

Colombo, A., Karvouni, E., 2000. Biodegradable stents - filling the mission and stepping away. Circulation 102, 371-373.

Dell-Erba, R., Groeninckx, G., Maglio, G., Malinconico, M., Migliozzi, A., 2001. Immiscible polymer blends of semicrystalline biocompatible components: thermal properties and phase morphology analysis of plla/pcl blends. Polymer 42, $7831-7840$.

Di Lorenzo, M.L., 2006. Calorimetric analysis of the multiple melting behavior of poly(llactic acid). J. Appl. Polym. Sci. 100, 3145-3151.

Grabow, N., Martin, D.P., Schmitz, K.P., Sternberg, K., 2010. Absorbable polymer stent technologies for vascular regeneration. J. Chem. Technol. Biotechnol. 85, 744-751.

Gui, Z., Lu, C., Cheng, S., 2013. Comparison of the effects of commercial nucleation agents on the crystallization and melting behaviour of polylactide. Polym. Test. 32, 15-21.

Kweon, H.Y., Yoo, M.K., Park, I.K., Kim, T.H., Lee, H.C., Lee, H.-S., Oh, J.-S., Akaike, T., Cho, C.-S., 2003. A novel degradable polycaprolactone networks for tissue engineering. Biomaterials 24, 801-808.

Lunt, J., 1998. Large-scale production, properties, and commercial applications of polylactic acid polymers. Polym. Degrad. Stab. 59, 145-152.

Luy, S.-P., Bates, F.S., Macosko, C.W., 2000. Coalescence in polymer blends during shearing. Am. Inst. Chem. Eng. J. 46, 229-238.

Luyt, A.S., Gasmi, S., 2016. Influence of blending and blend morphology on the thermal properties and crystallization behaviour of PLA and PCL in PLA/PCL blends. J. Mater. Sci. 51, 4670-4681.

Na, Y.-H., He, Y., Shuai, X., Kikkawa, Y., Doi, Y., Inoue, Y., 2002. Compatibilization effect of poly( $\varepsilon$-caprolactone)-b-poly(ethylene glycol) block copolymers and phase morphology analysis in immiscible poly(lactide)/poly( $\varepsilon$-caprolactone) blends. Biomacromolecules 3, 1179-1186.

Nair, L.S., Laurencin, C.T., 2007. Biodegradable polymers as biomaterials. Prog. Polym. Sci. 32, 762-798.

Ormiston, J.A., Serruys, P.W.S., 2009. Bioabsorbable coronary stents. Circ. Cardiovasc. Interv. 2, 255-260.

Peng, T., Gibula, P., Yao, K., Goosen, M.F.A., 1996. Role of polymers in improving the results of stenting in coronary arteries. Biomaterials 17, 685-694.

Rasal, R.M., Janorkar, A.V., Hirt, D.E., 2010. Poly(lactic acid) modifications. Prog. Polym. Sci. 35, 338-356.

Shan, G.-F., Yang, W., Tang, X.-G., Yang, M.-B., Xie, B.-H., Fu, Q., Mai, Y.-W., 2010. Multiple melting behaviour of annealed crystalline polymers. Polym. Test. 29, 273-280.

Silva, W.J., Seneviratne, J., Parahitiyawa, N., Rosa, E.A.R., Samaranayake, L.P., Del Bel Cury, A.A., 2008. Improvement of XTT assay performance for studies involving Candida albicans biofilms. Braz. Dent. J. 19, 364-369.

Sjögren, G., Sletten, G., Dahl, J.E., 2000. Cytotoxicity of dental alloys, metals, and ceramics assessed by millipore filter, agar overlay, and MTT tests. J. Prosthet. Dent. 84, 229-236.

Sundararaj, U., 2006. Phase morphology development in polymer blends: processing and experimental aspects. In: Harrats, C., Thomas, S., Groeninckx, G. (Eds.), Micro and Nanostructured Multiphase Polymer Blend Systems - Phase Morphology and Interfaces.. Taylor \& Francis, Florida, 133-164.

Sundararaj, U., Macosko, C.W., 1995. Drop breakup and coalescence in polymer blends: the effects of the concentration and compatibilization. Macromolecules 28, 2647-2657.

Tamai, H., Igaki, K., Kyo, E., Kosuga, K., Kawashima, A., Matsui, S., Komori, H., Tsuji, T., Motohara, S., Uehata, H., 2000. Initial and 6-month results of biodegradable poly-llactic acid coronary stents in humans. Circulation 25, 399-404.

Tsuji, H., Yamada, T., Suzuki, M., Itsuno, S., 2003. Blends of aliphatic polyesters part 7. effects of poly(l-lactide-co-e-caprolactone) on morphology, structure, crystallization, and physical properties of blends of poly(l-lactide) and poly( $\varepsilon$-caprolactone). Polym. Int. 52, 269-275.

Van Puyvelde, P., Velankar, S., Moldenaers, P., 2001. Rheology and morphology of compatilized polymer blends. Curr. Opin. Colloid Interface Sci. 6, 457-463.

Williamson, M.R., Coombes, A.G.A., 2004. Gravity spinning of polycaprolactone fibres for applications on tissue engineering. Biomaterials 25, 459-465.

Wong, B.S., Teoh, S.-H., Kang, L., 2012. Polycaprolactone scaffold as targeted drug delivery system and cell attachment scaffold for postsurgical. Drug Deliv. Transl. Res. 2, 2272-2283.

Woodruff, M.A., Hutmacher, D.W., 2010. The return of a forgotten polymerpolycaprolactone in the 21st century. Prog. Polym. Sci. 35, 1217-1256.

Work, W.J., 2004. Definitions of terms related to polymer blends, composites, and multiphase polymeric materials. Pure Appl. Chem. 76, 1985-2007.

Yalkinoglu, A.Ö., Schlehofer, J.R., Zur Hausen, H., 1990. Inhibition of N-methyl-N”nitro-n-nitrosoguanidine-induced methotrexate and adriamycin resistance in $\mathrm{CHO}$ cells by adeno-associated virus type 2 . Int. J. Cancer 45, 1195-1203.

Yasuniwa, M., Tsubakihara, S., Iura, K., Ono, Y., Dan, Y., Takahashi, K., 2006. Crystallization behavior of poly(l-lactic acid). Polym. 47, 7554-7563.

Zeng, J.-B., Li, K.-A., Du, A.-K., 2015. Compatibilization strategies in poly(lactic acid)based blends. R. Soc. Chem. Adv. 5, 32546-32565.

Zhang, C., Zhai, T., Turng, L.-S., Dan, Y., 2015. Morphological, mechanical, and crystallization behavior of polylactide/polycaprolactone blends compatibilized by llactide/caprolactone copolymer. Ind. Eng. Chem. Res. 54, 9505-9511.

Zhou, H., Green, T.B., Joo, Y.L., 2006. The thermal effects on electrospinning of polylactic acid melts. Polymer 47, 7497-7505. 